\title{
ÖZGÜN ARAȘTIRMA
}

Batı Karadeniz Tıp Dergisi

Medical Journal of Western Black Sea
Med J West Black Sea 2021;5(1): 94-100

DOI: $10.29058 /$ mjwbs.

\section{Foramen Infraorbitale'nin Üç Boyutlu Rekonstrüksiyon Yöntemi ille Değerlendirilmesi}

\author{
Evaluation of Foramen Infraorbitale by Three Dimensional \\ Reconstruction Method
}

\author{
Șengül TEKEMEN (D), Ayșe Zeynep YILMAZER KAYATEKiN² (D), Kerem ATALAR ${ }^{2}$ (D), \\ Cenk Murat ÖZER ${ }^{2}$ \\ 1 Zonguldak Bülent Ecevit Üniversitesi, Sağlık Bilimleri Enstitüsü, Anatomi Anabilim Dalı, Zonguldak, Türkiye \\ ${ }^{2}$ Zonguldak Bülent Ecevit Üniversitesi Tıp Fakültesi Anatomi Anabilim Dalı, Zonguldak, Türkiye
}

ORCID ID: Șengül Tekemen 0000-0001-9659-2693, Ayșe Zeynep Yılmazer Kayatekin 0000-0003-1144-382X, Kerem Atalar 0000-0003-1239-1144, Cenk Murat Özer 0000-0002-7813-723X

Bu makaleye yapılacak atıf: Tekemen S, Yılmazer Kayatekin AZ, Atalar K, Özer CM. Foramen Infraorbitale'nin Üç Boyutlu Rekonstrüksiyon Yöntemi İle Değerlendirilmesi. Med J West Black Sea. 2021;5(1):94-100.

Bu çalıșma Zonguldak Bülent Ecevit Üniversitesi Sağlık Bilimleri Enstitüsü Anatomi Anabilim Dalı'nda Sengül Tekemen tarafından yazılan ve tez danıșmanı Dr. Ögrr. Üyesi Cenk Murat Özer olan 650323 no'lu, "Foramen Infraorbıtale'nin Üç Boyutlu Rekonstrüksiyon Yöntemi Ile Değerlendirilmesi" isimli yüksek lisans tezinden üretilmiștir.

Sorumlu Yazar

Ayșe Zeynep Yılmazer Kayatekin

E-posta

aysezeynepyilmazer@hotmail.com

Geliș Tarihi

10.11.2020

Revizyon Tarihi

12.02.2021

Kabul Tarihi

19.02.2021 öz

Amaç: Bu çalışmanın amacı, üç boyutlu rekonstrüksiyon yöntemi ile elde edilen bilgisayarlı tomografi (BT) görüntüleri üzerinde foramen infraorbitale'nin yeri ve belli referans noktalara olan uzaklıklarının değerlendirilmesidir.

Gereç ve Yöntemler: Bu çalışmada, Bülent Ecevit Üniversitesi Tıp Fakültesi Radyoloji Anabilim Dalı'nda herhangi bir nedenle yüz bölgesinde inceleme yapılan 50 kişiye ait maksillofasiyal BT görüntüleri kullanıldı. Foramen infraorbitale'nin sekiz referans noktaya olan uzaklığı ölçüldü. Foramen infraorbitale'den iki referans noktasına çizilen çizgi ile foramen infraorbitale'den orta hatta çekilen dikey çizgi arasında tanımlanan iki açı ölçüldü.

Bulgular: Elde edilen verilerle; toplam kişi, kadın ve erkeklerde taraf karşılaştırması ile sol ve sağ tarafta cinsiyet karşılaştırması yapıldı. Taraf karşılaştırmasında; toplam kişilerde ve erkeklerde foramen infraorbitale ve orta hat arasındaki uzaklıkta (AM), kadınlarda ise foramen infraorbitale ve apertura piriformis arasındaki uzaklıkta (AF) istatistiksel olarak anlamlı farklılık saptandı $(p<0,05)$. Cinsiyet karşılaştırmasında; sol tarafta foramen infraorbitale ve arcus zygomathicus'un en dış kenarından çekilen dik çizgi arasındaki uzaklıkta (AE) ve foramen infraorbitale ve spina nasalis anterior arasındaki uzaklıkta $(A H)$ anlamlı farklılık saptandı $(p<0,05)$. Sağ tarafta $A M, A E, A F$, foramen infraorbitale ve nasion arasındaki uzaklık ( $A G)$ ve $A H$ uzaklığında istatistiksel olarak anlamlı farklılık saptandı $(p<0,05)$.

Sonuç: Foramen infraorbitale'nin yerinin bilinmesi o bölgeye yapılacak girişimler açısından önem taşımaktadır. Bu bölgedeki anatomik yapılarla ilgili üç boyutlu rekonstrüksiyon çalışmaları sınırlıdır. BT, foramen infraorbitale'nin lokalizasyonunun ayrıntılı bir şekilde incelenmesini sağlayabilir.

Anahtar Sözcükler: Foramen infraorbitale, BT, Anatomi, Antropometri

\section{ABSTRACT}

Aim: The aim of this study is to evaluate the location of foramen infraorbitale and its distance from certain reference points on computed tomography (CT) images obtained by three-dimensional reconstruction method.

Materials and Methods: In this study, maxillofacial CT images of 50 people who were examined in the facial region for any reason at Bulent Ecevit University Faculty of Medicine Radiology Department were used. The distance of foramen infraorbitale to eight reference points was measured Two angles defined 
between the line drawn from the foramen infraorbitale to the two reference points and the vertical line drawn from the foramen infraorbitale to the midline were measured.

Results: With these data; side comparison was made amongst total people, women and men; gender comparison was made between the left and right sides. According to the side comparison, the distance between foramen infraorbitale and midline (AM) was found statistically significantly different in total people and men. In addition, the distance between foramen infraorbitale and apertura piriformis (AF) was statistically significantly different in women $(p<0.05)$. According to the gender comparison, the distance between the foramen infraorbitale and the perpendicular line drawn from the outermost edge of arcus zygomathicus (AE) and the distance between the foramen infraorbitale and spina nasalis anterior $(\mathrm{AH})$ was found statistically significantly different $(\mathrm{p}<0.05)$. On the right side, $A M, A E, A F, A H$ and the distance between foramen infraorbitale and nasion (AG) was found statistically significantly different $(p<0.05)$.

Conclusion: As a result; knowledge of the location of foramen infraorbitale is important during the surgical interventions. Three-dimensional reconstruction studies related to the anatomical structures in this region are limited. CT can provide a detailed examination of the localization of foramen infraorbitale.

Keywords: Foramen infraorbitale, CT, Anatomy, Anthropometry

\section{Giriş}

Maxilla'nın facies orbitalis'inde arka kenardan başlayıp ortalara kadar uzanan sulcus infraorbitalis ön tarafta maxilla içinde canalis infraorbitalis olarak yukarı ve yana doğru devam eder. Canalis infraorbitalis, maxilla'nın margo infraorbitalis'inin alt orta bölümünde foramen infraorbitale ile maxilla'nın facies anterior'una açılır (1-3).

Foramen infraorbitale, içerisinde nervus (n.) infraorbitalis, arteria (a.) infraorbitalis ve vena (v.) infraorbitalis bulunan nörovasküler demetin fasiyal bölgeye geçişini sağlar $(4,5)$. Bu damar ve sinirler; yanakların, alt göz kapağının, burun dış yüzünün, üst dudakların, kesici ve premolar dişlerin beslenmesi ve innervasyonundan sorumludur $(1,6,7)$.

Foramen infraorbitale orbita, cavitas nasi, buccal bölgeler ve dişlere yakınlığı açısından önemli bir referans noktasına sahiptir (8). Bu nedenle ağız, çene ve yüz cerrahisinde, farklı tanısal cerrahi ve diğer invaziv işlemlerde kesin yeri ve anatomik oluşumlara olan mesafelerinin bilinmesi önemlidir (9-12).

Foramen infraorbitale çevresinde yapılan birçok cerrahi ve kozmetik işlemde, intraoperatif ve postoperatif ağrıda, inatçı ve farmakolojik tedaviye cevap vermeyen trigeminal nevralji'de infraorbital sinir bloğu kullanılır (13-15). Infraorbital sinir bloğu yapıldığında alt göz kapağı, burnun yan yüzü, üst dudak ve bunların arasındaki yanak bölgesinin anestezisi sağlanmış olur $(16,17)$.

Foramen infraorbitale'nin yerleşimi, anatomik yapısı, etrafında bulunan yapılar ve bunlarla ilişkisinin bilinmesi (6); o bölgeye yapılan işlemler sırasında, içinden geçen nörovasküler demete zarar verilmemesi için gereklidir (8).

Bu çalışmada üç boyutlu rekonstrüksiyon yöntemi kullanılarak elde edilen BT görüntüleri üzerinde; foramen infraorbitale'nin yeri ve belli referans noktalara olan uzaklıklarının değerlendirilmesi amaçlanmışır. Elde edilen sonuçların bu bölgede gerçekleştirilecek girişimsel tedavilerde klinisyenler için yol göstereci olabileceği düşünülmektedir.

\section{GEREÇ ve YÖNTEMLER}

Çalışmamıza Zonguldak Bülent Ecevit Üniversitesi Tıp Fakültesi Radyoloji Anabilim Dalı'nda; herhangi bir nedenle yüz bölgesinde inceleme yapılan 19-65 yaş arasında 19'u kadın, 31'i erkek olmak üzere toplam 50 kişiye ait maksillofasiyal BT görüntüleri değerlendirildi. Türk toplumu örneğinde incelenen BT görüntüleri arasında; yüz bölgesinde operasyon geçmişine veya herhangi bir patolojiye sahip olanlar çalışma kapsamına alınmadı. Çalışmamıza alınacak minimum denek sayısı 0,7 etki büyüklüğü, alfa=0,05 ve \%80 güç için 50 kişi olarak belirlenmiş ve ilgili hesaplama G*Power 3.1. paket programında, Zonguldak Bülent Ecevit Üniversitesi Tıp Fakültesi Biyoistatistik Anabilim Dalı'nda yapılmıştır. Çalışmamız için Zonguldak Bülent Ecevit Üniversitesi Klinik Araştırmalar Etik Kurulu'ndan 10.10.2018 tarih ve 2018/19 karar numaralı etik onayı alınmıştır.

Bu çalışmadaki ölçümler, BT görüntüleri üzerinde üç boyutlu rekonstrüksiyon yöntemi ile retrospektif (geriye dönük) olarak yapıldı. Seçilen BT görüntüleri, DICOM formatında OSIRIX programına yüklendi. OSIRIX programının 3D Volume Rendering özelliği ile kesitsel görüntüler 3 boyuta çevrildi ve en iyi görüntüyü sağlamak için yoğunluk ayarları yapıldı. Elde edilen görüntüde ölçüm noktalarının isimlendirmeleri yapıldı. Yapılan ölçümlerin tümünde, foramen infraorbitale'nin merkez noktası esas alındı.

Foramen infraorbitale'nin orta hatta olan uzaklığı (AM), foramen infraorbitale'nin margo supraorbitalis'e olan uzaklığı $(A B)$, foramen infraorbitale'nin margo infraorbitalis'e uzaklığı (AC), foramen infraorbitale'nin orbita lateral kenarından çekilen dik çizgiye olan uzaklığı (AD), foramen infraorbitale'nin arcus zygomathicus'un en dış kenarından çekilen dik çizgiye olan uzaklığı (AE), foramen infraorbitale'nin apertura piriformis'in dış kenarına olan uzaklığı (AF), foramen infraorbitale'nin nasion noktasına olan uzaklığı (AG), foramen infraorbitale'nin spina nasalis anterior'a olan uzaklığı $(A H)$, foramen infraorbitale'den nasion'a çekilen doğrunun açısı (GAM), foramen infraorbitale'nin spina nasalis anterior'a çe- 
kilen doğrunun açısı (MAH) olmak üzere on farklı parametre ölçüldü (Şekil 1).

Çalışmanın istatistiksel analizleri SPSS 19.0 paket programında yapıldı. Çalışmada yer alan değişkenlere ait tanımlayıcı istatistikler ortalama (ort.) ve standart sapma (SS) değerleri ile gösterildi. Nicel değişkenlerin normal dağılıma uygunluğu Shapiro Wilk testi ile test edildi. Değişkenlerin iki grup karşılaştırmalarında; sol ve sağ taraf karşılaştırmada paired samples t-test ve cinsiyetler arası karşılaştırmada independent samples t-test analizi kullanıldı. Değişkenler arası ilişki pearson korelasyon analizi ile incelendi. Çalışmadaki tüm istatistiksel analizlerde $p<0,05$ 'in altındaki karşılaştırmalar istatistiksel olarak anlamlı kabul edildi.

\section{BULGULAR}

Tablo 1'de toplam kişiler, kadınlar ve erkeklere ait parametrelerin sol ve sağ taraf karşılaştırmaları yapıldı. Bu tabloya göre toplam kişilerde sağ tarafın AM uzaklığı, sol tarafın AM uzaklığından istatistiksel olarak anlamlı derecede uzun bulundu $(p=0,008 ; p<0,05)$. Kadınlarda sol tarafın AF uzaklığı, sağ tarafın AF uzaklığından istatistiksel olarak anlamlı derecede uzun bulundu $(p=0,029 ; p<0,05)$. Erkeklerde sağ tarafın AM uzaklığı, sol tarafın AM uzaklığından istatistiksel olarak anlamlı derecede uzun bulundu $(p=0,018 ; p<0,05)$.
Tablo 2'de kadınlar ve erkeklere ait parametrelerin sol taraf karşılaştırmaları yapıldı. Erkeklerin sol taraf $\mathrm{AE}$ ve $\mathrm{AH}$ değerleri, kadınların sol taraf değerlerinden istatistiksel olarak anlamlı derecede uzun bulundu (sırasıyla $p=0,012$, $p=0,009 ; p<0,05)$.

Tablo 3'de kadınlar ve erkeklere ait parametrelerin sol taraf karşılaştırmaları yapıldı. Erkeklerde sağ taraf AM, AE, AF, $A G$ ve $A H$ uzaklığı, kadınlardaki sağ taraf uzaklığından istatistiksel olarak anlamlı derecede uzun bulundu (sırasıyla $p=0,014, p=0,04, p=0,002, p=0,045, p=0,013 ; p<0,05)$.

Kadınlarda sol tarafa ait tüm parametreler ile ilgili yapılan korelasyon değerlendirmesine göre, yaş ve AM parametreleri arasında istatistiksel olarak anlamlı pozitif yönlü orta derecede ilişki saptandı $(r=0,571 ; p<0,05)$. Yaş ve GAM parametreleri arasında istatistiksel olarak anlamlı negatif yönlü orta derecede ilişki belirlendi $(r=-0,481 ; p<0,05)$. Sağ tarafta ise yaş ve diğer parametreler arasında istatistiksel olarak anlamlı ilişki belirlenmedi ( $p>0,05)$.

Erkeklerde sol tarafa ait tüm parametreler ile ilgili yapılan korelasyon değerlendirmesine göre, sol tarafta yaş ve diğer parametreler arasında istatistiksel olarak anlamlı ilişki belirlenmedi $(p>0,05)$. Sağ tarafta ise yaş ve MAH parametreleri arasında istatistiksel olarak anlamlı negatif yönlü orta derecede ilişki saptandı $(r=-0,437 ; p<0,05)$.

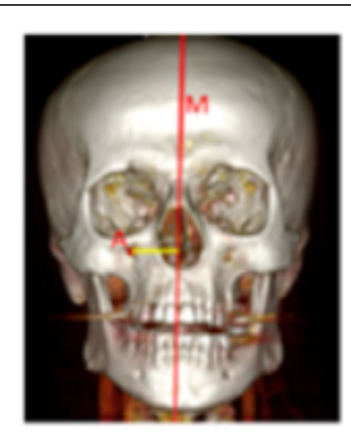

AM

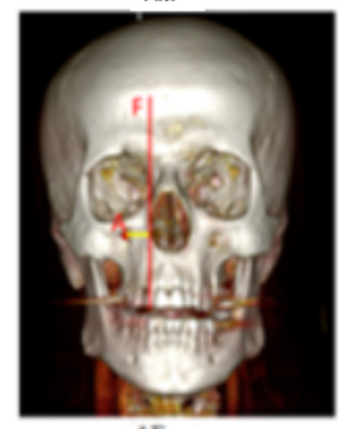

AF

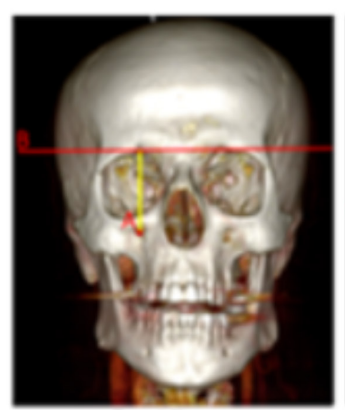

AB

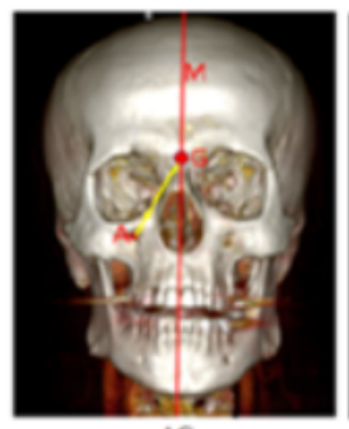

AC

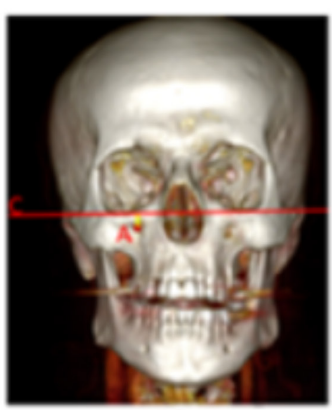

$\mathrm{AC}$

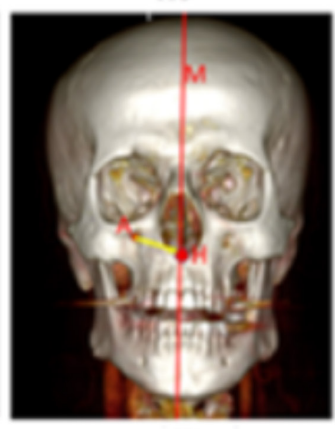

AH

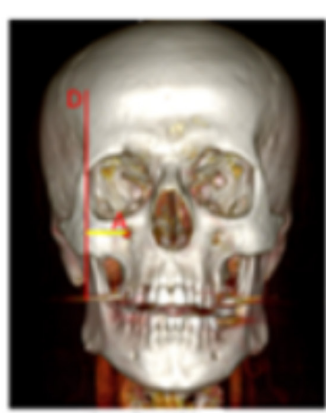

AD

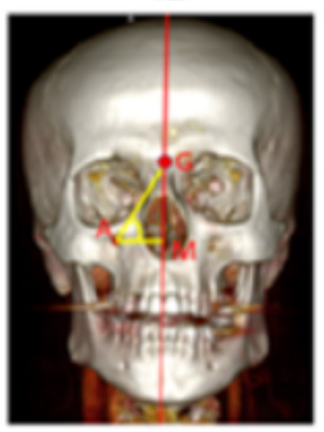

OAM

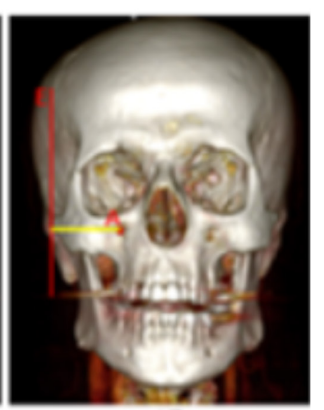

NE

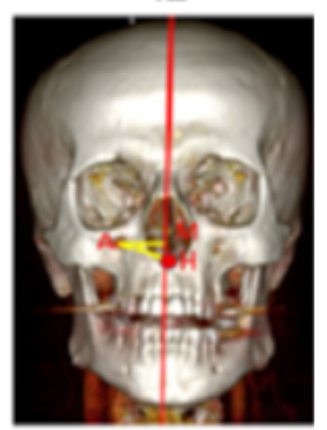

MUH

Şekil 1: Çalışmada yer alan parametreler. Foramen infraorbitale'nin merkezi (A), Orta hat (M), Margo supraorbitalis (B), Margo infraorbitalis (C), Orbita'nın lateral kenarı (D), Arcus zygomathicus'un en dış kenarı (E), Apertura piriformis'in dış kenarı (F), Nasion $(\mathrm{G})$, Spina nasalis anterior $(\mathrm{H})$. 
Tablo 1: Toplam kişiler, kadınlar ve erkeklerde sol ve sağ taraf parametrelerinin değerlendirilmesi (toplam kişi $n=50$, kadın $n=19$, erkek $\mathrm{n}=31$ ).

\begin{tabular}{|c|c|c|c|c|c|c|c|c|c|}
\hline \multirow{3}{*}{ Parametre } & \multirow{2}{*}{\multicolumn{2}{|c|}{ Toplam kişi }} & \multirow{3}{*}{ p } & \multirow{2}{*}{\multicolumn{2}{|c|}{$\begin{array}{l}\text { Kadın } \\
\bar{X} \pm s\end{array}$}} & \multicolumn{4}{|c|}{ Erkek } \\
\hline & & & & & & \multirow[t]{2}{*}{ p } & \multicolumn{2}{|c|}{$\bar{x} \pm s$} & \multirow[t]{2}{*}{ p } \\
\hline & Sol & Sağ & & Sol & Sağ & & Sol & Sağ & \\
\hline $\mathrm{AM}(\mathrm{mm})$ & $24,2 \pm 0,31$ & $25,3 \pm 0,31$ & 0,008 & $23,3 \pm 0,32$ & $24,0 \pm 0,33$ & 0,245 & $24,8 \pm 0,30$ & $26,2 \pm 0,28$ & 0,018 \\
\hline$A B(m m)$ & $42,5 \pm 0,34$ & $42,1 \pm 0,33$ & 0,217 & $41,9 \pm 0,34$ & $41,4 \pm 0,31$ & 0,284 & $42,9 \pm 0,34$ & $42,6 \pm 0,34$ & 0,463 \\
\hline $\mathrm{AC}(\mathrm{mm})$ & $10,1 \pm 0,35$ & $9,4 \pm 0,23$ & 0,173 & $9,7 \pm 0,27$ & $9,7 \pm 0,27$ & 0,863 & $10,3 \pm 0,40$ & $9,3 \pm 0,21$ & 0,168 \\
\hline $\mathrm{AD}(\mathrm{mm})$ & $22,9 \pm 0,26$ & $22,7 \pm 0,27$ & 0,643 & $22,6 \pm 0,25$ & $22,6 \pm 0,30$ & 0,912 & $23,1 \pm 0,26$ & $22,8 \pm 0,25$ & 0,555 \\
\hline $\mathrm{AE}(\mathrm{mm})$ & $40,5 \pm 0,38$ & $39,6 \pm 0,34$ & 0,051 & $38,8 \pm 0,32$ & $38,3 \pm 0,33$ & 0,442 & $41,5 \pm 0,37$ & $40,3 \pm 0,33$ & 0,075 \\
\hline AF $(\mathrm{mm})$ & $14,2 \pm 0,29$ & $14,1 \pm 0,29$ & 0,804 & $13,5 \pm 0,28$ & $12,5 \pm 0,28$ & 0,029 & $14,7 \pm 0,30$ & $15,1 \pm 0,25$ & 0,575 \\
\hline$A G(m m)$ & $44,2 \pm 0,44$ & $44,1 \pm 0,43$ & 0,611 & $43,1 \pm 0,45$ & $42,5 \pm 0,45$ & 0,132 & $44,9 \pm 0,43$ & $45,0 \pm 0,39$ & 0,736 \\
\hline GAM $\left({ }^{\circ}\right)$ & $55,06 \pm 4,13$ & $54,89 \pm 3,15$ & 0,794 & $55,43 \pm 4,69$ & $55,80 \pm 3,43$ & 0,704 & $54,83 \pm 3,82$ & $54,34 \pm 2,89$ & 0,548 \\
\hline $\mathrm{AH}(\mathrm{mm})$ & $30,5 \pm 0,31$ & $30,6 \pm 0,30$ & 0,749 & $29,1 \pm 0,27$ & $29,3 \pm 0,32$ & 0,621 & $31,4 \pm 0,31$ & $31,4 \pm 0,25$ & 0,933 \\
\hline MAH $\left(^{\circ}\right)$ & $35,00 \pm 6,62$ & $35,21 \pm 5,85$ & 0,772 & $34,74 \pm 6,43$ & $35,18 \pm 6,00$ & 0,704 & $35,15 \pm 6,84$ & $35,23 \pm 5,86$ & 0,938 \\
\hline
\end{tabular}

Pairedsamples t-testi, Foramen infraorbitale'nin merkezi (A), Orta hat (M), Margo supraorbitalis (B), Margo infraorbitalis (C), Orbita'nın lateral kenarı (D), Arcus zygomathicus'un en dış kenarı (E), Apertura piriformis'in dış kenarı (F), Nasion (G), Spina nasalis anterior (H).

Tablo 2: Sol tarafta kadın ve erkeklere ait parametrelerin değerlendirilmesi $(n=50)$.

\begin{tabular}{cccl}
\hline Parametre & $\begin{array}{c}\text { Kadın } \\
\bar{X} \pm \mathbf{s}\end{array}$ & $\begin{array}{c}\text { Erkek } \\
\bar{X} \pm \mathbf{s}\end{array}$ & $\mathbf{p}$ \\
\hline $\mathbf{A M}(\mathbf{m m})$ & $23,3 \pm 0,32$ & $24,8 \pm 0,30$ & 0,101 \\
\hline $\mathbf{A B}(\mathbf{m m})$ & $41,9 \pm 0,34$ & $42,9 \pm 0,34$ & 0,317 \\
\hline $\mathbf{A C}(\mathbf{m m})$ & $9,7 \pm 0,27$ & $10,3 \pm 0,40$ & 0,543 \\
\hline $\mathbf{A D}(\mathbf{m m})$ & $22,6 \pm 0,25$ & $23,1 \pm 0,26$ & 0,473 \\
\hline $\mathbf{A E}(\mathbf{m m})$ & $38,8 \pm 0,32$ & $41,5 \pm 0,37$ & $\mathbf{0 , 0 1 2}$ \\
\hline $\mathbf{A F}(\mathbf{m m})$ & $13,5 \pm 0,28$ & $14,7 \pm 0,30$ & 0,183 \\
\hline $\mathbf{A G}(\mathbf{m m})$ & $43,1 \pm 0,45$ & $44,9 \pm 0,43$ & 0,177 \\
\hline $\mathbf{G A M}\left({ }^{\circ}\right)$ & $55,43 \pm 4,69$ & $54,83 \pm 3,82$ & 0,646 \\
\hline $\mathbf{A H}(\mathbf{m m})$ & $29,1 \pm 0,27$ & $31,4 \pm 0,31$ & $\mathbf{0 , 0 0 9}$ \\
\hline MAH $\left({ }^{\circ}\right)$ & $34,74 \pm 6,43$ & $35,15 \pm 0,84$ & 0,833 \\
\hline
\end{tabular}

Independent samples t-test, Foramen infraorbitale'nin merkezi $(A)$, Orta hat $(M)$, Margosupraorbitalis $(B)$, Margo infraorbitalis $(C)$, Orbita'nınlateral kenarı (D), Arcus zygomathicus'un en dış kenarı $(E)$, Apertura piriformis'in dış kenarı $(F)$, Nasion $(G)$, Spina nasalis anterior $(\mathrm{H})$.

\section{TARTIŞMA}

Yüz bölgesinde yer alan deliklerin anatomik özelliklerinin önemi, bu bölgede gerçekleştirilecek cerrahi işlemlerde artış göstermektedir (3). Foramen infraorbitale'nin, foramen supraorbitale/incisura supraorbitalis ile aynı düzlemde olduğu kabul edilmektedir (3) ve yerini belirleyebilmek için direkt radyografi $(18,19)$ ve ultrasonografi (USG) (20) gibi farklı metodlar kullanılmaktadır (3,22-24). Foramen infraorbitale'nin, margo infraorbitalis'in 1-1,5 cm altından palpasyon
Tablo 3: Sağ tarafta kadın ve erkeklere ait parametrelerin değerlendirilmesi $(n=50)$.

\begin{tabular}{lccc}
\hline Parametre & $\begin{array}{c}\text { Kadın } \\
\bar{X} \pm \mathbf{s}\end{array}$ & $\begin{array}{c}\text { Erkek } \\
\bar{X} \pm \mathbf{s}\end{array}$ & p \\
\hline AM $(\mathbf{m m})$ & $24,0 \pm 0,33$ & $26,2 \pm 0,28$ & $\mathbf{0 , 0 1 4}$ \\
\hline $\mathbf{A B}(\mathbf{m m})$ & $41,4 \pm 0,31$ & $42,6 \pm 0,34$ & 0,206 \\
\hline $\mathbf{A C}(\mathbf{m m})$ & $9,7 \pm 0,27$ & $9,3 \pm 0,21$ & 0,594 \\
\hline $\mathbf{A D}(\mathbf{m m})$ & $22,6 \pm 0,30$ & $22,8 \pm 0,25$ & 0,880 \\
\hline $\mathbf{A E}(\mathbf{m m})$ & $38,3 \pm 0,33$ & $40,3 \pm 0,33$ & $\mathbf{0 , 0 4 0}$ \\
\hline $\mathbf{A F}(\mathbf{m m})$ & $12,5 \pm 0,28$ & $15,1 \pm 0,25$ & $\mathbf{0 , 0 0 2}$ \\
\hline $\mathbf{A G}(\mathbf{m m})$ & $42,5 \pm 0,45$ & $45,0 \pm 0,39$ & $\mathbf{0 , 0 4 5}$ \\
\hline $\mathbf{G A M}\left({ }^{\circ}\right)$ & $55,80 \pm 3,43$ & $54,34 \pm 2,89$ & 0,130 \\
\hline AH $(\mathbf{m m})$ & $29,3 \pm 0,32$ & $31,4 \pm 0,25$ & $\mathbf{0 , 0 1 3}$ \\
\hline MAH $\left.\mathbf{(}^{\circ}\right)$ & $35,18 \pm 6,00$ & $35,23 \pm 5,86$ & 0,980 \\
\hline
\end{tabular}

Independent samples t-test, Foramen infraorbitale'nin merkezi $(A)$, Orta hat (M), Margosupraorbitalis (B), Margo infraorbitalis (C), Orbita'nınlateral kenarı (D), Arcus zygomathicus'un en dış kenarı $(E)$, Apertura piriformis'in dış kenarı $(F)$, Nasion $(G)$, Spina nasalis anterior $(\mathrm{H})$.

yapılarak belirlenebilmesi de mümkündür. Ancak foramen infraorbitale'nin anatomik varyasyonları nedeniyle yalnızca palpasyonla yerini belirlemek kolay olmayabilir $(20,21)$.

Foramen infraorbitale'nin merkez noktası esas alınan çaışmamızda AM uzaklığı taraf karşılaştırmasında, toplam kişi ve erkeklerde sağ taraf değerlerinin daha uzun olduğu saptandı. İsmail ve Al-Rafai, konik ışınlı BT görüntülerinde üç boyutlu rekonstrüksiyon yöntemi ile foramen infraorbitale'nin medial sınırı ile orta hat arasındaki uzaklığı 
değerlendirmiştir. Çalışmalarında taraf karşılaştırmasında anlamlı farklılık olmadığı, sol ve sağ taraflara göre yapılan cinsiyet karşılaştırmasında ise sol tarafta ise erkek değerlerinin uzun olduğu bildirilmiştir (22). Çalışmamızda, İsmail ve ark.nın çalışmasının aksine cinsiyet karşılaştırmasında; sağ tarafta erkek değerlerinin daha uzun olduğu saptandı.

Bazı çalışmalarda foramen infraorbitale ile margo infraorbitalis arası uzaklığın 5-10 mm (23) / 10 mm (13, 24-27) olduğu bildirilmiş̧ir. Bizim çalışmamızda ort. \pm SS değerleri; toplamda sol tarafta $10,1 \pm 0,35 \mathrm{~mm}$, sağ tarafta $9,4 \pm 0,23$ $\mathrm{mm}$, kadınlarda sol tarafta $9,7 \pm 0,27 \mathrm{~mm}$, sağ tarafta $9,7 \pm$ $0,27 \mathrm{~mm}$, erkeklerde sol tarafta $10,3 \pm 0,40 \mathrm{~mm}$, sağ tarafta $9,3 \pm 0,21 \mathrm{~mm}$ saptandı.

Literatür taramalarımızda $A E$ uzaklığı ile ilgili, bizim çalışmamıza benzer çalışmalara rastlanılmaması çalışmamıza değer katmaktadır. Çalışmamızda hem sol ve hem sağ tarafta yapılan cinsiyet karşılaştırmasında, her iki tarafta da erkek değerleri daha uzun bulundu.

Apertura piriformis, yüz bölgesinde kolaylıkla hissedilebilir. Bu nedenle AF uzaklığı foramen infraorbitale'nin yerinin belirlemesinde, rahatıkla kullanılabilecek uzaklıklardan biri olabilir. Çalışmamızda taraf karşılaşıımasında, kadınlarda sol tarafta daha uzun bulunduğundan asimetri, erkeklerde simetri olduğu söylenebilir. Toplam kişilerde taraflar arasında anlamlı farklılık olmadığını saptadığımız çalışmamız, Tewari ve ark. cinsiyeti bilinmeyen 61 kuru kafatası üzerinde yaptıkları ve taraflar arasında istatistiksel olarak anlamI farklılık olduğunu bildirirdikleri çalışmadan ayrılmaktadır (28). Cinsiyet karşılaştırmasında, AF sağ tarafta erkek değerleri daha uzun bulundu ancak sol tarafta anlamlı farklılık görülmedi. Bjelakovic ve ark.nın multi dedektörlü BT ile yaptıkları çalışmalarında, sol ve sağ taraf cinsiyet karşılaşı̧ımasında, her iki tarafta erkek değerlerinin daha uzun olduğu bildirilmiştir (5).

Çalışmamızda foramen infraorbitale'nin nasion noktasına olan uzaklığı (AG) parametresinde taraf karşılaştırmasında farklııı saptanmadı, simetri olduğu söylenebilir. Cinsiyet karşılaştırmamızda ise sağ tarafta erkeklere ait değerler daha uzun bulundu. Bakırcı ve ark., iki döneme ait kafataslarında (günümüz ve Bizans dönemi) çalışma gerçekleştirmişlerdir. İki dönemin karşılaştırmasında; sağ tarafta Bizans dönemi değerlerinin daha uzun olduğu verilmiştir $(29,30)$. Sol tarafta ve toplamda anlamlı farklılık bildirilmemiştir. Klinikte erkeklerde yapılacak işlemlerde AG uzaklı̆ıında taraflarda asimetri olabileceği göz önüne alınabilir.

Çalışmamızda foramen infraorbitale'nin spina nasalis anterior'a olan uzaklığı $(\mathrm{AH})$ toplam kişi, kadın ve erkelerde taraf karşılaşıtırmasında, anlamlı farklıık göstermedi. Ukoha ve ark.nın kuru kafatasında kumpas ile yaptıkları çalışmalarında; taraf karşılaştırmasında ise sağ taraf değerlerinin daha uzun olduğu bildirilmiştir (15). Sol ve sağ tarafta cinsi- yet karşılaştırmasında, her iki tarafta erkek değerleri daha uzun bulundu. Oliveira ve ark.nın, kuru kafatası üzerinde dijital kumpas ile yapılan çalışmasında; cinsiyet karşılaştırmasında AH uzaklığı erkek değerlerinin daha uzun olduğu bildirilmiştir (25). Bu durum çalışmamızı desteklemektedir ve erkeklerin kafa büyüklüğü ile açıklanabilir.

Foramen infraorbitale ve ilişkili olduğu anatomik yapılarla ilgili üç boyutlu rekonstrüksiyon çalışmaları sınırıdır. Literatür taramalarımızda $A E$ uzaklığı, GAM açısı ve MAH açısı ile igili çalışmaya rastlanılmaması çalışmamıza değer katmaktadır. Çalışmada elde edilen verilerle; toplam kişi, kadın ve erkeklerde taraf karşılaştırması ile sol ve sağ tarafta cinsiyet karşılaştırması yapıldı.

Taraf karşılaştırmasında; toplam kişilerde ve erkeklerde AM uzaklığı ile kadınlarda AF uzaklığında istatistiksel olarak anlamlı farklıık saptandı $(p<0,05)$. Toplam kişilerde ve erkeklerde AM uzaklığı sağ tarafta daha uzun, kadınlarda AF uzaklığı sol tarafta daha uzun bulundu. Diğer parametrelerde anlamlı farklılık bulunmadı.

Cinsiyet karşılaştırmasında; sol tarafta AE ve AH uzaklığında anlamlı farklılık saptandı $(p<0,05)$ ve erkeklerde daha uzun olduğu görüldü. Sağ tarafta cinsiyet karşılaştırmasında; $A M, A E, A F, A G$ ve $A H$ uzaklığında istatistiksel olarak anlamlı farklıık saptandı $(p<0,05)$ ve erkeklerde daha uzun olduğu görüldü. Diğer parametrelerde anlamlı farklılık bulunmadı $(p>0,05)$.

Foramen infraorbitale'nin belli referans noktalara olan uzaklık değerlerinin ve farklılıklarının bilgisinin, klinik uygulamalarda yüz cerrahisi, diş tedavileri, kozmetik, akupunktur gibi birçok işlemde kullanılabileceğini düşünüyoruz. Yüz bölgesindeki simetrinin değerlendirilmesinin, bu işlemlerde kolaylık sağlayabileceğine inanıyoruz. BT'nin foramen infraorbitale'nin lokalizasyonunun ayrıntılı bir şekilde incelenmesini sağlayabileceğini ve foramen infraorbitale ile ilgili çalışmaların artması ile cinsiyet ve taraf farklılıklarını daha ayrıntılı belirlenebileceğini düşünüyoruz.

\section{Teşekkür}

Çalışmamızın istatistiksel analizini yapmamızda bize yardımcı olan Zonguldak Bülent Ecevit Üniversitesi Biyoistatistik Anabilim Dalı Öğretim Üyesi Mustafa Çağatay BÜYÜKUYSAL'a teşekkür ederiz.

\section{Yazar Katkı Beyanı}

Bu çalışma Kerem Atarlar ve Cenk Murat Özer tarafından planlanmıştır. Araştırmaya dair ölçümler Şengül Tekemen tarafından yapılmışıı. Araştırmanın istatistiksel sonuçları Şengül Tekemen dışındaki diğer üç yazar tarafından ortak olarak değerlendirilmiştir. Makale kısmı Şengül Tekemen ve Ayşe Zeynep Yılmazer Kayatekin tarafından yazılmışırı. Cenk Murat Özer ve Kerem Atalar tarafından kontrol edilmiş ve düzenlenmiştir. 


\section{Çıkar Çatışması}

Bu çalışmada yer alan yazarlardan hiçbiri herhangi bir çıkar elde etmemiştir.

\section{Finansal Destek}

Çalışmamız için herhangi bir finansal destek kullanılmamıştır.

\section{Etik Kurul Onayı}

Çalışmamız için Zonguldak Bülent Ecevit Üniversitesi Klinik Araştırmalar Etik Kurulu'ndan 10.10.2018 tarih ve 2018/19 karar numaralı etik onayı alınmıştır.

Hakemlik Süreci

Kör hakemlik süreci sonrası yayınlanmaya uygun bulunmuş ve kabul edilmiştir.

\section{KAYNAKLAR}

1. Arıncı K, Elhan A. Anatomi. 3. Basım, Ankara, Güneş Kitabevi, 2001, 1. Cilt, s.47; 2. Cilt, s.32, 13.

2. Sancak B, Cumhur M. Fonksiyonel Anatomi: Baş-Boyun ve İç Organlar. 11. Basım, Ankara, ODTÜ Geliştirme Vakfı Yayıncılık, 2017, s.11.

3. Ülker E. Foramen infraorbitale'nin yetişkin kuru kafa ve kadavralardaki yerleşimi ve komşu yumuşak dokularla olan ilişkisinin incelenmesi. Isparta, Süleyman Demirel Üniversitesi, Sağlık Bilimleri Enstitüsü, Yüksek Lisans Tezi, 2010.

4. Bahşi I, Orhan M, Kervancıoğlu P, Yalçın ED. Morphometric evaluation and surgical implications of the infraorbital groove, canal and foramen on cone beam computed tomography and review of literature. Folia Morphologica 2019;78(2):331-343.

5. Bjelakovic MD, Popovic J, Stojanov D, Dzopalic T, Ignjatovic J. Morphometric characteristics of the infraorbital foramen on volume rendered CT scans. RAD Association Journal 2017; 2,3: 204-206.

6. Bahşi I. Nervus maxillaris ve dallarinin anestezi bölgelerinin radyolojik anatomïsi. Gaziantep, Gaziantep Üniversitesi, Sağıı Bilimleri Enstitüsü, Doktora Tezi, 2017.

7. Uzun Ç, Şanverdi ŞE, Üstüner E, Gürses MA, Şalvarlı Ş. Evaluation of Infraorbital canal anatomy and related anatomical structures with multi detector Ct. Ankara Üniversitesi Tıp Fakültesi Mecmuası 2016; 69: 89-91.

8. Demirtaş İ. Üç boyutlu multi dedektör bilgisayarlı tomografide orbita ve orbital yapıların morfometrik analizi. Afyonkarahisar, Afyon Kocatepe Üniversitesi, Sağlık Bilimleri Enstitüsü, Yüksek Lisans Tezi, 2014.

9. Karapınar Umar E. Konik ışınlı bilgisayarlı tomografi kullanılarak infraorbital foramen, infraorbital kanal, infraorbital sulcus ve çevre yapıların anatomik olarak retrospektif incelenmesi. Erzurum, Atatürk Üniversitesi, Sağlık Bilimleri Enstitüsü, Doktora Tezi, 2015.

10. Chrcanovic BR, Nogueira MH, Abreu G, Custódio ALN. A morphometric analysis of supraorbital and infraorbital foramina relative to surgical landmarks. Surg Radiol Anat 2011; 33:329335.
11. Varshney R, Sharma N. Supraorbital foramen morphometric study and clinical application in adult Indian skulls. Acta Medica International 2013; 2(3): 151-154.

12. Tezer M, Öztürk A, Akgül M, Gayretli Ö, Kale A. Anatomic and morphometric features of the accessory infraorbital foramen. Journal of Morphological Sciences 2011; 28(2): 95-97.

13. Ilayperuma I, Nanayakkara G, Palahepitiya N. Morphometric analysis of the infraorbital foramen in adult Sri Lankan skulls. International Journal of Morphology 2010; 28(3): 777-778.

14. Zide BM, Swift R. How to block and tackle the face. Plast Reconstr Surg 1997; 101(3): 840-851.

15. Ukoha UU,Umeasalugo KH, Udemezue OO, Nzeako HC, Ndukwe GU, Nwankwo PC. Anthropometric measurement of Infraorbital foramen in South-East and South-South Nigeria. National Journal of Medical Research 2014; 4(3): 225-227.

16. Joseph CC, Soman MA, Jacob M, Nallathamby R. Morphometric variations in infraorbital foramen of dry adult human South Indian skulls with its surgical and anaesthetic significance. International Journal of Health Sciences and Researc 2015; 5(1): 130-132.

17. Koçyiğit $P$, Güner MA. Kozmetik ve cerrahi uygulamalar için yüz anatomisi. Turk J Dermatol 2015; 3: 115-22

18. Kara SA, Ünal B, Erdal H, Huvaj S, Koç C. İnfraorbital Foramen Anatomisinin Radyolojik Analizi. KBB ve BBC Dergisi 2003; 11(1): 17-21

19. Kazkayasi M, Ergin A, Ersoy M, Tekdemir i, Elhan A. Microscopic anatomy of the infraorbital canal, nerve and foramen. Otolaryngology Head and Neck Surgery 2003; 129(6): 692-697.

20. Tsui $\mathrm{BCH}$. Ultrasound imaging to localize foramina for superficial trigeminal nerve block. Canadian Journal Anesthesia 2009; 56: 704-706.

21. Lim SM, Park HL, Moon HY, Kang KH, Kang H, Baek CH, Jung YH, Kim JY, Koo GH, Shin Hy. Ultrasound-guided infraorbital nerve pulsed radiofrequency treatment for intractable postherpetic neuralgia. Korean Journal of Pain 2013; 26 (1): 84-88.

22. Ismail RS, Al-Rafai AS. Morphometric analysis of infra orbital foramen by a cone beam computed tomography. Medical Journal of Babylon 2016; 13(4): 741-749.

23. Dixit SG, Kaur J, Nayyar AK, Agrawal D. Morphometric analysis and anatomical variations of infraorbital foramen: A study in adult North Indian populatio. Morphologie 2014; 98: 2-3.

24. Nithya Karpagam G, Thenmozhi MS. A study of morphometric analysis of infraorbital foramen in South Indian dry skulls. Journal of Pharmaceutical Sciences and Research, 2016; 8(11): 1318-1319.

25. Oliveira LCSC, Silveira MPM, Júnior EA, Reis F P, Aragão JA Morphometric study on the infraorbital foramen in relation to sex and side of the cranium in northeastern Brazil. Anatomy \& Cell Biology 2016; 49(1): 73-75.

26. Singh R. Morphometric analysis of infraorbital foramen in Indian dry skulls. Anatomy Cell \& Biology 2011; 44: 79-80.

27. Veeramuthu M, Varman R, Shalini, Manoranjitham. Morphometric analysis of infraorbital foramen and incidence of accessory foramen and its clinical implications in dry adult human skull. International Journal of Anatomy and Research 2016; 4(4): 2993-2994. 
Tekemen $S$ et al.

28. Tewari S, Gupta C, Palimar V, Kathur S. Morphometric analysis of infraorbital foramen in South Indian dry skulls. Bangladesh Journal of Medical Science 2018; 17: 562-563.

29. Bakirci S, Kafa IM, Coskun I, Buyukuysal MC, Barut C. A comparison of anatomical measurements of the infraorbital foramen of skulls of the modern and late byzantine periods and the golden ratio. International Journal of Morphology 2016; 34 : 790-792.
30. Bakirci S, Kafa IM, Coskun I, Buyukuysal MC, Barut C. A comparison of the relationship between the golden ratio and anatomical characteristics of the supraorbital foramen in bare skulls belonging to the byzantine era and modern era. International Journal of Morphology 2016;34(2):671-678. 